in vivo $35: 3527-3535(2021)$

doi:10.21873/invivo.12655

\title{
Quality of Life in Swiss Patients With Spongiform Venous Malformations
}

\author{
BOJAN SPAHIC ${ }^{1,2}$, DANIEL G. HASSELMANN ${ }^{1}$, MICHAEL KOSTRZEWA ${ }^{3,4}$, \\ THOMAS O. MEIER ${ }^{2}$, STEPHAN ENGELBERGER ${ }^{1}$ and ROBERT K. CLEMENS ${ }^{1}$ \\ ${ }^{1}$ Vascular Center, Cantonal Hospital Baden, Baden, Switzerland; \\ ${ }^{2}$ Clinic for Angiology, University Hospital Zurich and University Zurich, Zurich, Switzerland; \\ ${ }^{3}$ Interventional Radiology, Department of Radiology, Cantonal Hospital Baden, Baden, Switzerland; \\ ${ }^{4}$ Department of Clinical Radiology and Nuclear Medicine, University Medical Center Mannheim, \\ Medical Faculty Mannheim, Heidelberg University, Mannheim, Germany
}

\begin{abstract}
Background/Aim: Spongiform venous malformations $($ sVMs) get symptomatic in $>90 \%$ of cases during a person's lifetime. Misdiagnosis is still common and treatment often incomplete, making this disease a lifelong issue for patients with a relevant impact on their quality of life. Patients and Methods: Medical records and imaging studies of patients with VMs from April 2002 to January 2017 were reviewed for confirmation of diagnosis and classification of the VMs. Only sVMs were included. Subjective data were obtained from the survey related to indication, response, and complications. We analyzed the frequency of correct diagnosis and Quality of Life by an SF12based questionnaire for sVM-related issues in Swiss patients. Results: A total of 80 patients were included in the study. Fortysix $(58 \%)$ patients were females. Patients were 11.6-77 years old with a median age of 28.1 years. The correct diagnosis according to the ISSVA-classification after having been seen at our Institution was $87 \%$. Thirty-one (39\%) patients responded to the survey. Sixteen (51\%) were female. Twenty-eight (90\%) patients felt that their sVM-related state of health improved within a year. Twelve (39\%) patients reported that they could not work as good as normal because of slight to modest impairment by the sVM, while 19 (61\%) patients were unimpaired. Mental impairment was found in 8 (26\%) patients, while 23 (74\%) patients felt no impairment. Eight (26\%) patients reported that they were impaired within social contacts due to their sVM. Only $9(29 \%)$ patients reported that venous malformation was
\end{abstract}

This article is freely accessible online.

Correspondence to: Robert K. Clemens, Vascular Center, Cantonal Hospital Baden, Im Ergel 1, 5404 Baden, Switzerland. Tel: +41 449222308, e-mail: robert.clemens@gmx.net

Key Words: Spongiform venous malformation, quality of life, survey, vascular malformation, misdiagnosis. diagnosed around birth. Twenty-three (74\%) patients received a wrong diagnosis. Patients that were treated, reported close to complete relief of symptoms in $26 \%$ (8 patients) while also $26 \%$ (8 patients) reported no change of symptoms after therapy. Conclusion: Swiss sVM patients also suffer from misdiagnosis and late diagnosis. They are impacted in their daily life by their disease.

Venous malformations (VMs) are dysmorphic venous channels that present in various ways (1). They can be relatively localized but also extensive within one or more anatomic regions. Venous malformations can be divided in 4 types: Spongiform, aneurysmal, reticular and phlebectatic (1). Spongiform venous malformations (sVMs) are the most often treated vascular malformations as these lesions get symptomatic in $>90 \%$ during lifetime $(2,3)$. VMs have typical cellular characteristics, such as flat endothelium, dysplastic walls, and thin basement membranes (4). The head, limbs, or trunk are the main locations, but they are also found in the internal viscera, bones and in skeletal muscle (5). It is assumed that $100 \%$ of VMs are present at birth, and more mutations responsible for venous malformations become identified such as a gene that codes for an endothelial receptor on chromosome $9 p$ (6). In general, single lesions are mostly due to a somatic mutation while multiple lesions are often caused by a hereditary genetic mutations (7). Superficial VMs are clinical apparent at birth, but are often misdiagnosed (8). While $>90 \%$ of VMs progress during childhood and in younger adults, the cause of natural progression in older people is unknown and may be due to softening of the vein walls as in primary varicose veins. The primary indication for invasive treatment of VMs is pain, which mostly results from recurrent intralesional thrombosis. Treatment indication is also given when VM involve the airways, or those with articular involvement or disfigurement as well as gastro-intestinal bleeding (9-12). As 


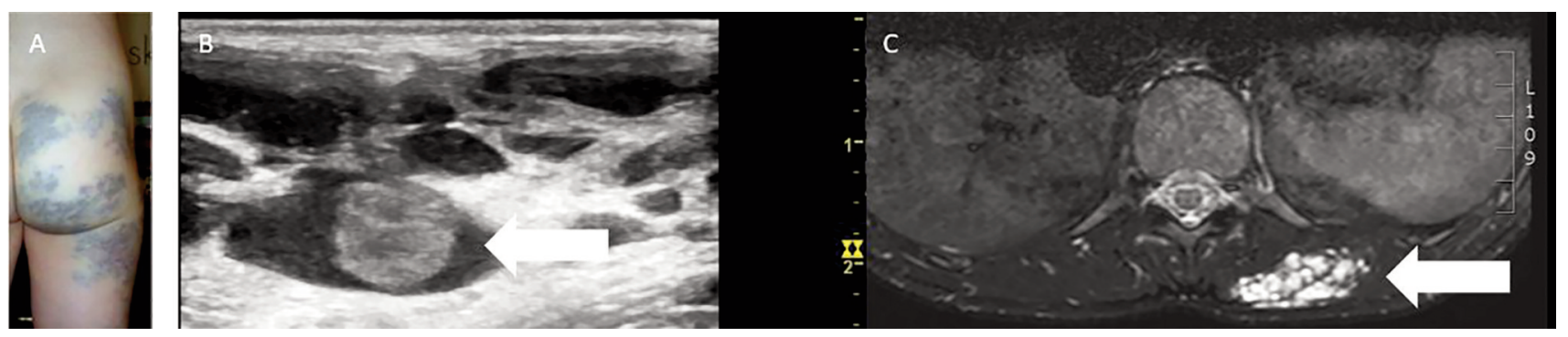

Figure 1. Spongiform venous malformation. (A) Venous malformation with typical appearance. (B) Ultrasound image of spongiform venous malformation with recent thrombosis (arrow). (C) T2-fat-saturated image of spongiform venous malformation of deep back muscle (arrow).

VMs in general enlarge over time, treatment should be initiated early, as smaller lesions are easier to treat (8). Small, painless VMs of the extremities can be managed conservatively sometimes by wearing compression stocking while first-line treatment of symptomatic spongiform venous malformations (sVMs) is sclerotherapy with Aethoxysclerol (normally in a 3\% concentration), dehydrated ethanol, sodium tetradecyl sulfate $3 \%$ (STS) and bleomycin being the most common sclerosants $(13,14)$ (Figure 1). The recurrence rate after incomplete removal is high and postoperative complications like damage to nerves are common, especially in case of surgical treatment (15).

Complete cure is possible, but treatment is often incomplete, making this disease a lifelong issue for patients with a relevant impact on their quality of life (16). Other studies assessed the outcome and complications of sclerotherapy for lymphatic malformations as well as for venous malformations performed have shown a decrease of symptoms after treatment (17-20). The SF Quality of Life Questionnaire (SF-12) questionnaire is frequently used to assess quality of life (QoL) after medical interventions (2123). We conducted a retrospective analysis based on the SF 12 Quality of Life Questionnaire Version 2 (SF-12) of (un)treated sVMs to assess quality with or without treatment as well as rates of misdiagnosis and other sVM-related issues in Swiss patients.

\section{Patients and Methods}

This study protocol was approved by the cantonal Ethics Committee and is in accordance with the guidelines of Helsinki. Medical records and imaging studies of patients with VMs from April 2002 through January 2017 were reviewed. Imaging studies were reviewed by specialists with experience in the diagnosis of vascular anomalies for confirmation of the diagnosis and classification of the VMs. Demographic and clinical data extracted from medical records and imaging studies included age, sex, anatomic location of the VM. Only sVMs were included. Subjective data was obtained from the survey related to indication, response, and complications. Patient's and/or their guardians/caregivers were sent a 21 -item survey. The first part was based on the 12-SF questionnaire on quality of life, while the second part was adopted to a questionnaire previously used in assessment of VMs.

Inclusion criteria: Patients with sVms. Exclusion criteria: Patients with VMs that are not of the spongiform type or other vascular malformations. Anatomical regions of VM location and treatment were categorized as: 1 . Head/neck. 2. Upper extremities. 3. Lower extremities. 4. Torso. 5. Multiple.

Data was extracted from medical records included demographics, and medical history. Specifically, anatomic location of VMs, correctness of diagnose when referred and after clinical visit, and treatment were noted. Imaging studies included CT-scans, MRIs, and ultrasound imaging.

Surveys were sent to 80 patients. If they did not respond they were sent a second survey. If they did not respond to the second survey, they were contacted via phone or email and if the patient agreed, a third questionnaire was sent. Of these 80 patients, 31 patients (39\%) responded to the survey. These 31 patients were included in the survey analysis.

The survey consisted of two parts: A) SF 12 health related to venous malformation, B) Venous malformation related. The survey questionnaire included 21 items either on a subjective one-to-three, or a one-to-five-grade scale.

Quality control (Q/C) was assured through back-checking of entered data against the original questionnaires. The entries were double checked by a second investigator. Frequency distributions were double checked. Incomplete, incorrect, inaccurate, and irrelevant data was removed from the final database to ensure accuracy and completeness.

\section{Results}

We included 80 patients with sVMs into this retrospective cohort study and analyzed their data. Forty-six (58\%) patients were female. Patients were 11.6-77 years old with a median age of 28.1 years. The correct diagnosis based on external or internal imaging as well as clinical visits when seen at our institution according to the ISSVA-classification was $88.8 \%$. All lesions were identified as vascular anomalies. Baseline characteristics are presented in Table I. Seventy patients received interventions. These patients were 11.6-71 years old at intervention with a median age of 31.5 years.

The survey results are presented in Table II. Not all patients' answers are displayed in detail to keep a clear view 
Table I. Baseline characteristics of included patients.

\begin{tabular}{lc}
\hline Baseline characeristics & \\
\hline All patients & \\
Number of patients & 80 \\
Gender female/male & $46 / 34$ \\
Age in years & $11.6-71.0$ \\
Median age in years & 28.1 \\
Median age at intervention in years & 31.5 \\
Correct diagnosis & $71(88.8 \%)$ \\
No. of patients that responded to survey & 31 \\
Gender female/male & $16 / 15$ \\
Age & $12.3-71.0$ \\
Median age & 29.6 \\
Correct diagnostics & $27(87 \%)$ \\
Area treated (total number of treatments in $\%)$ & \\
Head/neck & $1(1)$ \\
Torso & $1(1)$ \\
Lower extremeties & $14(26)$ \\
Upper extremeties & $9(22)$ \\
Multiple locations & $1(5)$ \\
\hline
\end{tabular}

on the focus of this paper. Thirty-one (39\%) patients responded and sent back the survey. Sixteen $(51 \%)$ of the responding patients were female. Responding patients were 12.3-71 years old with a median age of 29.6 years. Of the patients that responded to the survey, 26 had received treatment. Treated areas were head/neck $1(4 \%)$, torso 1 (4\%), upper extremities 9(35\%), lower extremities 14 (54\%) and multiple locations in $1(4 \%)$ case.

The first part of the survey was based on the SF12 questionnaire for Quality-of-Life version 2 and referred to the influence of the sVMs on the QoL. Two questions compared the actual state of health to the state of health related to the venous malformation a year ago. Twenty-eight $(90 \%)$ patients felt that their sVM-related state of health was better (either excellent, very good or good), while only 3 $(10 \%)$ patients reported a worse state of health ("less good" or "bad").

One question focused on how physical abilities in daily life (such as heavy work, walking, carrying bags, and 6 other items) were impaired by the sVM. Only $3(10 \%)$ patients reported that they were strongly impaired by the sVM, while $11(30 \%)$ patients were slightly impaired, and $18(58 \%)$ patients were not impaired when performing strenuous activity. If walking more than 1,000 meters, 6 (20\%) patients felt impaired, while $25(80 \%)$ did not. Twelve (39\%) patients reported that they couldn't work as good as normal because of slight to modest impairment by the sVM during the last 4 weeks, while $19(61 \%)$ patients were unimpaired. Being asked if they were mentally impaired (being sad, feeling bad, etc.) by the malformation, $8(26 \%)$ patients reported some impairment, while 23 (74\%) patients felt no impairment.
Three more questions focused on this subject bearing the same response and outcome. Correlating to this, $8(26 \%)$ patients reported that they were impaired within social contacts during the last 4 weeks.

The last question focusing on the QoL focused on whether the patients felt a tendency of being sick (not only related to the VM but the general health) compared to their peer group. Only few $3(10 \%)$ patients felt that they were sicker or had a higher tendency towards other diseases than their peer group.

The second part of the survey was directly related to VM. Only $9(29 \%)$ patients reported that VM was diagnosed around birth. The other patients received diagnosis during their lifetime. Twenty-three (74\%) patients received a wrong diagnosis before the VM was diagnosed correctly. This means that only $26 \%$ (8) patients were diagnosed correctly when having been examined for their VM for the first time. Common misdiagnosis was "hemangioma", "tumor", or "cystic hygroma" amongst others. Twenty-six (84\%) patients reported increase of the symptoms during their lifetime, with a slow progression within in the last 5 years and $22(71 \%)$ patients an even slower progression before that. Nine (30\%) patients reported an increase of the lesion due to a defined event, such as pregnancy.

Being asked about symptoms, most patients complained about pain 29 (94\%) and swelling 27 (87\%). Previous infections were mentioned by $2(6 \%)$ patients. Five (16\%) patients felt very disturbed by their physical appearance due to the malformation, while $16(52 \%)$ patients reported minor disturbance due to their physical appearance related to the sVM. Ten $(32 \%)$ patients were very worried about possible complications due to the sVM and $10(32 \%)$ patients less concerned. Eleven (35\%) patients were not concerned about complications. Patients were asked how often the sVM was symptomatic: Nine (30\%) patients reported that the sVM was symptomatic every day; six (19\%) patients reported symptoms on a weekly base; eight $(26 \%)$ patients reported monthly symptoms, and $5(16 \%)$ patients reported yearly symptoms. Twenty-six (84\%) patients reported active treatment of the sVM. Sixteen $(52 \%)$ patients received sclerotherapy, $4(13 \%)$ patients reported additional endovenous laser ablation. Surgical procedures were performed in $12(39 \%)$ cases. Additional compression therapy in extremity sVMs was performed in $8(26 \%)$ patients and $8(26 \%)$ patients received painkillers for treatment of symptomatic lesions.

Eight $(26 \%)$ patients that had received active treatment (such as sclerotherapy) reported a relevant relief of symptoms, while also $26 \%$ (8 patients) reported no change of symptoms after such therapy. Seven (23\%) patients reported a long-lasting relief of symptoms while 3 (10\%) patients reported relief for some time after treatment but no permanent relief. Nine (29\%) patients reported complications after any therapy, such as relevant pain and swelling after 
Table II. Survey results.

\begin{tabular}{|c|c|c|c|c|c|c|c|c|c|c|}
\hline \multirow{2}{*}{$\begin{array}{l}\text { Question } \\
\text { How would you describe } \\
\text { your state of health in general? }\end{array}$} & \multicolumn{2}{|c|}{ Excellent } & \multicolumn{2}{|c|}{ Very good } & \multicolumn{2}{|c|}{ Good } & \multicolumn{2}{|c|}{ Less good } & \multicolumn{2}{|c|}{$\mathrm{Bad}$} \\
\hline & 5 & $16 \%$ & 10 & $32 \%$ & 13 & $42 \%$ & 1 & $3 \%$ & 2 & $6 \%$ \\
\hline Question & \multicolumn{2}{|c|}{$\begin{array}{l}\text { Much better } \\
\text { than a year ago }\end{array}$} & \multicolumn{2}{|c|}{$\begin{array}{l}\text { Somewhat better } \\
\text { than a year ago }\end{array}$} & \multicolumn{2}{|c|}{$\begin{array}{l}\text { About the same } \\
\text { as a year ago }\end{array}$} & \multicolumn{2}{|c|}{$\begin{array}{l}\text { Somewhat worse } \\
\text { than a year ago }\end{array}$} & \multicolumn{2}{|c|}{$\begin{array}{l}\text { Much worse } \\
\text { than a year ago }\end{array}$} \\
\hline $\begin{array}{l}\text { Compared to last year, how would } \\
\text { you rate your current state of health? }\end{array}$ & 2 & $6 \%$ & 4 & $13 \%$ & 21 & $68 \%$ & 3 & $10 \%$ & 1 & $3 \%$ \\
\hline \multicolumn{11}{|c|}{ Question } \\
\hline \multicolumn{3}{|c|}{$\begin{array}{l}\text { Does your current health condition } \\
\text { make you unable to perform these activities? }\end{array}$} & & & \multicolumn{2}{|c|}{$\begin{array}{l}\text { Yes, strong } \\
\text { limitations }\end{array}$} & \multicolumn{2}{|c|}{$\begin{array}{l}\text { Yes, somewhat } \\
\text { limited }\end{array}$} & \multicolumn{2}{|c|}{$\begin{array}{c}\text { No, not restricted } \\
\text { at all }\end{array}$} \\
\hline \multicolumn{5}{|c|}{ 3.1 Strenuous activity e.g., fast running, sports } & 2 & $6 \%$ & 11 & $35 \%$ & 18 & $58 \%$ \\
\hline \multicolumn{5}{|c|}{$\begin{array}{l}\text { 3.2 Medium activity } e . g . \text {, Vacuum cleaning, } \\
\text { moving the table, playing golf }\end{array}$} & 0 & $0 \%$ & 7 & $23 \%$ & 24 & $77 \%$ \\
\hline \multicolumn{5}{|c|}{ 3.3 Lift or carry shopping bags } & 3 & $10 \%$ & 4 & $13 \%$ & 24 & $77 \%$ \\
\hline \multicolumn{5}{|l|}{ 3.4 Climb several stairs } & 0 & $0 \%$ & 3 & $10 \%$ & 28 & $90 \%$ \\
\hline \multicolumn{5}{|l|}{ 3.5 Climb a single stair } & 0 & $0 \%$ & 1 & $3 \%$ & 30 & $97 \%$ \\
\hline \multicolumn{5}{|l|}{ 3.6 Bend, bend your knee } & 1 & $3 \%$ & 5 & $16 \%$ & 25 & $81 \%$ \\
\hline \multicolumn{5}{|l|}{3.7 Walk more than $1 \mathrm{~km}$} & 2 & $6 \%$ & 4 & $13 \%$ & 25 & $81 \%$ \\
\hline \multicolumn{5}{|l|}{ 3.8 Walk several hundred meters } & 0 & $0 \%$ & 2 & $6 \%$ & 29 & $94 \%$ \\
\hline \multicolumn{5}{|l|}{ 3.9 Walk one hundred meters } & 0 & $0 \%$ & 2 & $6 \%$ & 29 & $94 \%$ \\
\hline \multicolumn{5}{|l|}{ 3.10 Bathing or dressing } & 0 & $0 \%$ & 1 & $3 \%$ & 29 & $94 \%$ \\
\hline \multicolumn{5}{|l|}{ Total average } & 1 & $3 \%$ & 4 & $13 \%$ & 26 & $84 \%$ \\
\hline
\end{tabular}

\section{Question}

Last 4 weeks, how many times

did you visit the hospital

due to your physical difficulties

at work or at home?

Always

Mostly

Sometimes

Rare

Never

4.1 I could not work as usual

4.2 I have achieved less than I wanted

4.3 I could only do certain things 1

4.4 I had difficulties with the execution 1

Total average

$\begin{array}{llll}1 & 3 \% & 1 & 3 \% \\ 0 & 0 \% & 2 & 6 \% \\ 1 & 3 \% & 3 & 10 \% \\ 1 & 3 \% & 3 & 10 \% \\ 0 & 2 \% & 2 & 7 \%\end{array}$

$3 \% \quad 6 \quad 19 \%$

$6 \% \quad 5 \quad 16 \%$

$10 \% \quad 5 \quad 16 \%$

$10 \% \quad 5 \quad 16 \%$

5
17

$16 \%$
$16 \%$

$54 \%$

\begin{tabular}{llll}
\multicolumn{2}{c}{ Rare } & \multicolumn{2}{c}{ Never } \\
\hline 4 & $13 \%$ & 19 & $61 \%$ \\
5 & $16 \%$ & 19 & $61 \%$ \\
3 & $10 \%$ & 19 & $61 \%$ \\
4 & $13 \%$ & 18 & $58 \%$ \\
4 & $13 \%$ & 19 & $60 \%$
\end{tabular}

Question

Last 4 weeks, how many times

have you felt down or anxious

due to mental issues or any other

difficulties at work or at home?

Always

Mostly

Sometimes

Rare

Never

$\begin{array}{lllllllllll}5.1 \text { I could not work as usual } & 1 & 3 \% & 1 & 3 \% & 3 & 10 \% & 7 & 23 \% & 19 & 61 \%\end{array}$

5.2 I got less done than I wanted

5.3 I could not work as careful

as I used to work

Total average

$\begin{array}{lll}1 & 3 \% & 3 \% \\ 1 & 2 & 6 \%\end{array}$

$\begin{array}{ll}3 & 10 \% \\ 5 & 16 \%\end{array}$

$13 \%$

$1 \quad 3 \% \quad 2$

$3 \% \quad 3$

$10 \%$

$5 \quad 16 \%$

$\begin{array}{ll}5 & 16 \% \\ 5 & 16 \%\end{array}$

18

$58 \%$

\begin{tabular}{|c|c|c|c|c|c|c|c|c|c|c|}
\hline \multirow{2}{*}{$\begin{array}{l}\text { Question } \\
\text { How much did your physical or } \\
\text { mental health problems affect } \\
\text { your daily contact with your family, } \\
\text { friends, neighbors, or acquaintances } \\
\text { in the last four weeks? }\end{array}$} & \multicolumn{2}{|c|}{ Not at all } & \multicolumn{2}{|c|}{ Somewhat } & \multicolumn{2}{|c|}{ Moderate } & \multicolumn{2}{|c|}{ Quite } & \multicolumn{2}{|c|}{ Very } \\
\hline & 23 & $74 \%$ & 4 & $13 \%$ & 1 & $3 \%$ & 3 & $10 \%$ & 0 & $0 \%$ \\
\hline
\end{tabular}

Table II. Continued 
Table II. Continued

Question

How often in the past 4 weeks

have you been

Full of life?

Very nervous?

So down that nothing

could cheer you up?

Calm and exuberant?

Full of energy?

Discouraged and sad?

Exhausted?

Happy?

Tired?

Total average

\begin{tabular}{|c|c|c|c|c|c|c|c|c|c|}
\hline \multicolumn{2}{|c|}{ Always } & \multicolumn{2}{|c|}{ Mostly } & \multicolumn{2}{|c|}{ Sometimes } & \multicolumn{2}{|c|}{ Rare } & \multicolumn{2}{|c|}{ Never } \\
\hline 11 & $35 \%$ & 10 & $32 \%$ & 8 & $26 \%$ & 1 & $3 \%$ & 0 & $0 \%$ \\
\hline 0 & $0 \%$ & 3 & $10 \%$ & 6 & $19 \%$ & 13 & $42 \%$ & 9 & $29 \%$ \\
\hline 0 & $0 \%$ & 1 & $3 \%$ & 5 & $16 \%$ & 9 & $29 \%$ & 16 & $52 \%$ \\
\hline 4 & $13 \%$ & 17 & $55 \%$ & 3 & $10 \%$ & 6 & $19 \%$ & 0 & $0 \%$ \\
\hline 5 & $16 \%$ & 15 & $48 \%$ & 7 & $23 \%$ & 3 & $10 \%$ & 1 & $3 \%$ \\
\hline 0 & $0 \%$ & 3 & $10 \%$ & 5 & $16 \%$ & 9 & $29 \%$ & 14 & $45 \%$ \\
\hline 1 & $3 \%$ & 0 & $0 \%$ & 12 & $39 \%$ & 12 & $39 \%$ & 5 & $16 \%$ \\
\hline 9 & $29 \%$ & 16 & $52 \%$ & 5 & $16 \%$ & 0 & $0 \%$ & 1 & $3 \%$ \\
\hline 2 & $6 \%$ & 6 & $19 \%$ & 15 & $48 \%$ & 6 & $19 \%$ & 2 & $6 \%$ \\
\hline 4 & $11 \%$ & 8 & $25 \%$ & 7 & $24 \%$ & 7 & $21 \%$ & 5 & $17 \%$ \\
\hline
\end{tabular}

\section{Question}

To what extent does each of the

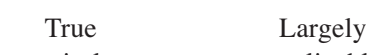

following statements apply to you?

entirely

applicable

Don't know

Does not apply

to a large extent

Does not apply

\begin{tabular}{|c|c|c|c|c|c|c|c|c|c|c|}
\hline $\begin{array}{l}\text { I seem to get sick more } \\
\text { easily than others }\end{array}$ & 1 & $3 \%$ & 5 & $16 \%$ & 6 & $19 \%$ & 7 & $23 \%$ & 12 & $39 \%$ \\
\hline $\begin{array}{l}\text { I am as healthy as other people } \\
\text { I know }\end{array}$ & 11 & $35 \%$ & 11 & $35 \%$ & 3 & $10 \%$ & 4 & $13 \%$ & 2 & $6 \%$ \\
\hline $\begin{array}{l}\text { I expect my health condition } \\
\text { to deteriorate }\end{array}$ & 1 & $3 \%$ & 2 & $6 \%$ & 7 & $23 \%$ & 11 & $35 \%$ & 10 & $32 \%$ \\
\hline My health is excellent & 8 & $26 \%$ & 12 & $39 \%$ & 2 & $6 \%$ & 5 & $16 \%$ & 4 & $13 \%$ \\
\hline Total Average & 5 & $15 \%$ & 7 & $24 \%$ & 7 & $23 \%$ & 6 & $21 \%$ & 5 & $17 \%$ \\
\hline
\end{tabular}

\begin{tabular}{|c|c|c|c|c|c|c|c|c|}
\hline \multirow{2}{*}{$\begin{array}{l}\text { Question } \\
\text { When were you first diagnosed } \\
\text { with venous malformation? }\end{array}$} & & & & & \multicolumn{2}{|c|}{ By birth } & \multicolumn{2}{|c|}{ Later } \\
\hline & & & & & 9 & $29 \%$ & 23 & $74 \%$ \\
\hline Question & & & & & \multicolumn{2}{|c|}{ Wrong diagnosis } & \multicolumn{2}{|c|}{ Correct diagnosis } \\
\hline $\begin{array}{l}\text { Was the venous malformation named } \\
\text { otherwise (e.g., as a hemangioma)? }\end{array}$ & & & & & 23 & $79 \%$ & 9 & $29 \%$ \\
\hline Question & \multicolumn{2}{|c|}{ Yes } & \multicolumn{2}{|c|}{ No } & \multicolumn{2}{|c|}{ Stable } & \multicolumn{2}{|c|}{ Become less } \\
\hline $\begin{array}{l}\text { Has the venous malformation } \\
\text { increased during your lifetime? }\end{array}$ & 26 & $81 \%$ & 3 & $9 \%$ & 2 & $6 \%$ & 0 & $0 \%$ \\
\hline $\begin{array}{l}\text { Have the complaints caused } \\
\text { by the venous malformation } \\
\text { increased over the years? }\end{array}$ & 14 & $44 \%$ & 10 & $31 \%$ & 5 & $16 \%$ & 3 & $9 \%$ \\
\hline
\end{tabular}

Question

How much is your life quality

limited due to the venous

malformation complaints?

Strong

Medium

Low

Not at all

Cannot say

A. Pain

B. Swelling

C. Infections

D. Appearance

E. Concerned about complications

F. Others

Total average

$\begin{array}{rrrr}4 & 13 \% & 10 & 32 \% \\ 3 & 9 \% & 10 & 31 \% \\ 0 & 0 \% & 0 & 0 \% \\ 5 & 16 \% & 6 & 19 \% \\ 5 & 16 \% & 5 & 16 \% \\ 2 & 13 \% & 4 & 27 \% \\ 3 & 11 \% & 6 & 20 \%\end{array}$

$\begin{array}{rrr}48 \% & 2 & 6 \% \\ 44 \% & 5 & 16 \% \\ 6 \% & 24 & 75 \% \\ 31 \% & 11 & 34 \% \\ 31 \% & 12 & 38 \% \\ 0 \% & 9 & 60 \% \\ 29 \% & 11 & 36 \%\end{array}$

\begin{tabular}{rr}
0 & $0 \%$ \\
0 & $0 \%$ \\
6 & $19 \%$ \\
0 & $0 \%$ \\
0 & $0 \%$ \\
0 & $0 \%$ \\
1 & $3 \%$ \\
\hline
\end{tabular}

Table II. Continued 
Table II. Continued

\begin{tabular}{|c|c|c|c|c|}
\hline \multirow{2}{*}{$\begin{array}{l}\text { Question } \\
\text { A. Have you carried out a treatment for venous malformation? }\end{array}$} & \multicolumn{2}{|c|}{ Yes } & \multicolumn{2}{|c|}{ No } \\
\hline & 26 & $81 \%$ & 4 & $13 \%$ \\
\hline A1 Sclerotherapy/Embolization & 63 & $80 \%$ & 16 & $20 \%$ \\
\hline A2 Laser treatment & 75 & $95 \%$ & 4 & $5 \%$ \\
\hline A3 Compression therapy & 71 & $90 \%$ & 8 & $10 \%$ \\
\hline A4 Operation & 67 & $85 \%$ & 12 & $15 \%$ \\
\hline A5 Blood thinning (LMWH, vKA, ASS) & 70 & $89 \%$ & 9 & $11 \%$ \\
\hline A6 Painkiller & 70 & $90 \%$ & 8 & $10 \%$ \\
\hline B. Overall, have the treatment(s) improved/reduced the symptoms? & 8 & $30 \%$ & 8 & $30 \%$ \\
\hline C. Are there any adverse events or adverse reactions during treatment? & 9 & $36 \%$ & 14 & $56 \%$ \\
\hline C1 Pain & 73 & $92 \%$ & 6 & $8 \%$ \\
\hline C2 Swelling & 72 & $91 \%$ & 7 & $9 \%$ \\
\hline C3 Thrombosis or phlebitis & 79 & $100 \%$ & 0 & $0 \%$ \\
\hline C4 Nerve damage & 74 & $94 \%$ & 5 & $6 \%$ \\
\hline C5 Wounds on the treated area & 76 & $96 \%$ & 3 & $4 \%$ \\
\hline C6 Other & 74 & $94 \%$ & 5 & $6 \%$ \\
\hline
\end{tabular}

ASS: Acetyl-salicyl-acid; LMWH: low molecular weight heparin; vKA: Vitamin K-antagonist.

sclerotherapy. Nerval injury after surgery was reported in 5 (16\%) patients. Ulceration after treatment appeared in 3 (10\%) patients. Deep venous vein thrombosis was not reported as complication.

\section{Discussion}

Misdiagnosis of patients with vascular malformations is still common. In this cohort, only the minority of patients received the correct diagnosis when examined for the first time. Correct diagnosis according to the ISSVA-classification was established after being seen at a University Hospital. Common misdiagnosis in this cohort was "hemangioma", "tumor", or "cystic hygroma" amongst others. These findings are consistent with above mentioned studies and reflect the problem of other rare diseases: a correct diagnosis is challenging and often results in a long odyssey for the patient $(8,24)$. Vascular malformations are often given different names depending on the classification used or on the clinical speciality that gives the diagnosis (24). It is not unusual that the same lesion is given multiple names within one scientific publication (25). Plenty of published articles, mostly case reports, give wrong diagnosis or mix up unrelated vascular anomalies, such as the "KlippelTrénaunay-Parkes-Weber-Syndrome"(26). When searching the National Library of Medicine $>30$ matches are found for "Klippel-Trénaunay-Parkes-Weber-Syndrome" when mentioned in the title, including Journals with a high Impact Factors. While KTS is a combined slow-flow lesion, PWS is a high-flow lesion with a different underlying genetic mutation $(26,27)$. There is an ongoing discussion on the topic of misnomers and correct diagnosis in vascular malformations $(28,29)$. Without vilifying the achievements of former and current researchers that have given particular names to circumscribed and defined vascular anomalies, the authors think in accordance with ISSVA that correct diagnosis of vascular malformations would benefit from the description of the involved vessel types (e.g., venous and lymphatic), adding information on under- and overgrowth and if possible, on the genetic underlying cause, and other important clinical findings, knowing, that wrong diagnosis causes wrong treatment in vascular anomalies (e.g., betablocker treatment in venous malformations) (30).

Pain and swelling, the main two complaints in patients within sVM, have a relevant impact on QoL and are the principal treatment indication. Data on QoL is available for different forms of venous diseases, such as DVT or pelvic congestion syndrome $(31,32)$. The negative impact of varicose veins on QoL and the positive effect after successful treatment is long known $(33,34)$. Evaluation of QoL after treatment of vascular malformations evaluated by surveys was performed earlier in relatively small cohorts. Berger et al. assessed Health-Related Quality of Life in a population of patients with VMs and compared the results with data from a national reference population in Norway (35). Their data also suggests that patients with vascular malformations impair QoL. They did compare cohort with the general population using the Short-Form 36-item questionnaire which also covers both physical and mental aspects and is the more extended form of the SF-12. We could confirm this finding in Swiss patients, that current health status was in $90 \%$ positive but $40 \%$ of patients reported impairment due to the sVM. A quarter of patients reported mental impairment due to the sVM. $26 \%$ patients reported that they were 
impaired within social contacts. QoL was also examined in conservatively managed patients as well as in active treated patients. Treatment of sVMs included invasive treatment (with sclerotherapy being the first-line treatment) and/or conservative treatment. Yun et al. found in their cohort of 207 patients who had been managed conservatively that based on responses to their questionnaire, the size and symptoms of VM progressed in $32 \%$ of patients over the course of their life (36). They could identify VMs combined with CM or LM as independent predictor of progression. The percentage of patients that had increasing symptoms due to the sVM was higher $(86 \%)$ in our cohort, which is in accordance with other published studies that showed progression of symptoms in $>90 \%$ (2). This high percentage of progression is also found in arteriovenous malformations and in lymphatic malformations $(37,38)$.

Rautio et al. included 23 patients that had completed treatment with ethanol sclerotherapy in their study and evaluated the quality of life after treatment, as well exploring psychological, physical, social functioning, and pain (39). Sixteen patients were symptomless after a year or more and the results concerning QoL showed that most patients did well after endovascular treatment. An overall degree of satisfaction with the treatment of craniofacial venous malformations in children and adults of $78 \%$ patients was reported by Berenguer et al. (40). Van der Linden et al. could also show that patient satisfaction was correlated to longterm outcome in VMs after treatment $(41,42)$. Their group achieved a sustainable improvement for half of the patients during a 5-year follow-up period. The above findings are in generally consistent with another study from 2017 that sclerotherapy for treatment of venous malformations results in significant reduction of symptoms. Despite multiple treatments needed patients were willing to undergo these (20). The recurrence rate after incomplete removal is high and postoperative complications like damage to nerves are common, especially in surgery (15). We could also confirm this in our cohort as nerve injury was the most frequent complication after surgery.

\section{Conclusion}

Although living in a country with one of the most advanced health care systems in the world, patients with vascular malformations still suffer from misdiagnosis, late diagnosis and incomplete treatment. They are impacted in their daily life by their disease. This leads us to the conclusion that in the adult medical community there still is a lack of awareness for vascular anomalies and that diagnosis and treatment should preferably be performed in specialized centers with a fix group of health personal working together. This group would be preferably from different specialties but should use the same nomenclature.

\section{Conflicts of Interest}

R.C. reports having received the "Förderungspreis USGG Switzerland" for this project. There are no other conflicts of interest.

\section{Authors' Contributions}

B.S. contributed to the data, performed the analysis, wrote the manuscript, and reviewed the paper. D.H. analyzed the data, wrote the paper, and reviewed the paper. M.K. contributed to the data and reviewed the paper. T.M. collected data, contributed to the data, and reviewed the paper. S.E. reviewed the results, contributed to the style, and reviewed the paper. R.C. designed the study, collected data, contributed to the data, wrote the paper, and reviewed the paper.

\section{Acknowledgements}

We thank Stéphanie Roth-Zetzsche for her logistical support.

\section{References}

1 Clemens RK, Lillis AP, Perez-Rossello J, Shaikh R, Thalhammer C, Amann-Vesti BR and Alomari AI: Misdiagnosis of plexiform neurofibroma as venous malformation in pediatric patients. Int Angiol 35(6): 613-621, 2016. PMID: 26868134.

2 Hassanein AH, Mulliken JB, Fishman SJ, Alomari AI, Zurakowski D and Greene AK: Venous malformation: risk of progression during childhood and adolescence. Ann Plast Surg 68(2): 198-201, 2012. PMID: 21629093. DOI: 10.1097/SAP. $0 \mathrm{~b} 013 \mathrm{e} 31821453 \mathrm{c} 8$

3 Clemens RK, Pfammatter T, Meier TO, Alomari AI and AmannVesti BR: Vascular malformations revisited. Vasa 44(1): 5-22, 2015. PMID: 25537054. DOI: 10.1024/0301-1526/a000402

4 Mulliken JB and Glowacki J: Hemangiomas and vascular malformations in infants and children: a classification based on endothelial characteristics. Plast Reconstr Surg 69(3): 412-422, 1982. PMID: 7063565. DOI: 10.1097/00006534-19820300000002

5 Hein KD, Mulliken JB, Kozakewich HP, Upton J and Burrows PE: Venous malformations of skeletal muscle. Plast Reconstr Surg 110(7): 1625-1635, 2002. PMID: 12447041. DOI: 10.1097/01.PRS.0000033021.60657.74

6 Boon LM, Mulliken JB, Vikkula M, Watkins H, Seidman J, Olsen BR and Warman ML: Assignment of a locus for dominantly inherited venous malformations to chromosome $9 \mathrm{p}$. Hum Mol Genet 3(9): 1583-1587, 1994. PMID: 7833915. DOI: $10.1093 / \mathrm{hmg} / 3.9 .1583$

7 Limaye N, Kangas J, Mendola A, Godfraind C, Schlögel MJ, Helaers R, Eklund L, Boon LM and Vikkula M: Somatic activating PIK3CA mutations cause venous malformation. Am J Hum Genet 97(6): 914-921, 2015. PMID: 26637981. DOI: 10.1016/j.ajhg.2015.11.011

8 Greene AK, Liu AS, Mulliken JB, Chalache K and Fishman SJ: Vascular anomalies in 5,621 patients: guidelines for referral. J Pediatr Surg 46(9): 1784-1789, 2011. PMID: 21929990. DOI: 10.1016/j.jpedsurg.2011.05.006

9 Ohlms LA, Forsen J and Burrows PE: Venous malformation of the pediatric airway. Int J Pediatr Otorhinolaryngol 37(2): 99-114, 1996. PMID: 8894808. DOI: 10.1016/0165-5876(96)01382-1 
10 Upton J and Taghinia A: Special considerations in vascular anomalies: operative management of upper extremity lesions. Clin Plast Surg 38(1): 143-151, 2011. PMID: 21095479. DOI: 10.1016/j.cps.2010.08.011

11 Blaise S, Charavin-Cocuzza M, Riom H, Brix M, Seinturier C, Diamand JM, Gachet G and Carpentier PH: Treatment of lowflow vascular malformations by ultrasound-guided sclerotherapy with polidocanol foam: 24 cases and literature review. Eur J Vasc Endovasc Surg 41(3): 412-417, 2011. PMID: 21111641. DOI: $10.1016 /$ j.ejvs.2010.10.009

12 Fishman SJ, Burrows PE, Leichtner AM and Mulliken JB: Gastrointestinal manifestations of vascular anomalies in childhood: varied etiologies require multiple therapeutic modalities. J Pediatr Surg 33(7): 1163-1167, 1998. PMID: 9694115. DOI: 10.1016/s0022-3468(98)90552-8

13 Mason KP, Michna E, Zurakowski D, Koka BV and Burrows PE: Serum ethanol levels in children and adults after ethanol embolization or sclerotherapy for vascular anomalies. Radiology 217(1): 127-132, 2000. PMID: 11012433. DOI: 10.1148/ radiology.217.1.r00se30127

14 de Lorimier AA: Sclerotherapy for venous malformations. J Pediatr Surg 30(2): 188-93; discussion 194, 1995. PMID: 7738736. DOI: 10.1016/0022-3468(95)90558-8

15 Mulliken JB, Fishman SJ and Burrows PE: Vascular anomalies. Curr Probl Surg 37(8): 517-584, 2000. PMID: 10955029. DOI: 10.1016/s0011-3840(00)80013-1

16 Fevurly RD and Fishman SJ: Vascular anomalies in pediatrics. Surg Clin North Am 92(3): 769-800, x, 2012. PMID: 22595720. DOI: $10.1016 /$ j.suc.2012.03.016

17 Alomari AI, Karian VE, Lord DJ, Padua HM and Burrows PE: Percutaneous sclerotherapy for lymphatic malformations: a retrospective analysis of patient-evaluated improvement. J Vasc Interv Radiol 17(10): 1639-1648, 2006. PMID: 17057006. DOI: 10.1097/01.RVI.0000239104.78390.E5

18 Burrows PE, Mitri RK, Alomari A, Padua HM, Lord DJ, Sylvia MB, Fishman SJ and Mulliken JB: Percutaneous sclerotherapy of lymphatic malformations with doxycycline. Lymphat Res Biol 6(3-4): 209-216, 2008. PMID: 19093794. DOI: 10.1089/lrb. 2008.1004

19 Chaudry G, Burrows PE, Padua HM, Dillon BJ, Fishman SJ and Alomari AI: Sclerotherapy of abdominal lymphatic malformations with doxycycline. J Vasc Interv Radiol 22(10): 1431-1435, 2011. PMID: 21821431. DOI: 10.1016/j.jvir. 2011.06.021

20 Clemens RK, Baumann F, Husmann M, Meier TO, Thalhammer C, MacCallum G, Amann-Vesti BR and Alomari AI: Percutaneous sclerotherapy for spongiform venous malformations - analysis of patient-evaluated outcome and satisfaction. Vasa 46(6): 477-483, 2017. PMID: 28841126. DOI: 10.1024/0301-1526/a000650

21 Yu CM, Lau CP, Chau J, McGhee S, Kong SL, Cheung BM and Li LS: A short course of cardiac rehabilitation program is highly cost effective in improving long-term quality of life in patients with recent myocardial infarction or percutaneous coronary intervention. Arch Phys Med Rehabil 85(12): 1915-1922, 2004. PMID: 15605326. DOI: 10.1016/j.apmr.2004.05.010

22 Sjögren J and Thulin LI: Quality of life in the very elderly after cardiac surgery: a comparison of SF-36 between long-term survivors and an age-matched population. Gerontology 50(6): 407-410, 2004. PMID: 15477702. DOI: 10.1159/000080179
23 Kurlansky PA, Williams DB, Traad EA, Carrillo RG, Schor JS, Zucker M and Ebra G: The influence of coronary artery disease on quality of life after mechanical valve replacement. J Heart Valve Dis 13(2): 260-271, 2004. PMID: 15086266.

24 Cohen MM Jr: Hemangiomas: their uses and abuses. Am J Med Genet A 143A(3): 235-240, 2007. PMID: 17163502. DOI: 10.1002/ajmg.a.31571

25 Yun WS, Kim DI, Rho YN, Do YS, Park KB, Kim KH, Park HS, Kim YW, Park UJ, Kim N and Woo SY: Natural course of venous malformation after conservative treatment. Surg Today 42(10): 950-955, 2012. PMID: 22535018. DOI: 10.1007/s00595012-0185-x

26 Bucek RA, Vavrik J, Minar E, Lammer J and Tscholakoff D: Images in cardiovascular medicine. Multimodality imaging of hemangiectasia hypertrophicans (Klippel-Trenaunay-ParkesWeber syndrome). Circulation 110(10): e295, 2004. PMID: 15353513. DOI: 10.1161/01.CIR.0000141806.36331.68

27 Alomari AI: Klippel-Trenaunay syndrome was not the correct answer. Arch Pediatr Adolesc Med 164(2): 203; authorreply204203; authorreply205, 2010. PMID: 20124155. DOI: 10.1001/ archpediatrics.2009.273

28 Uller W and Alomari AI: Misdiagnosis of Klippel-Trenaunay syndrome. Intern Med 53(5): 525, 2014. PMID: 24583451. DOI: 10.2169/internalmedicine.53.1295

29 Yamada T, Ohba T and Seino Y: Reply to the letter: Misdiagnosis of Klippel-Trenaunay syndrome. Intern Med 53(5): 527, 2014. PMID: 24583452. DOI: 10.2169/internalmedicine. 53.1514

30 Hassanein AH, Mulliken JB, Fishman SJ and Greene AK: Evaluation of terminology for vascular anomalies in current literature. Plast Reconstr Surg 127(1): 347-351, 2011. PMID: 21200229. DOI: 10.1097/PRS.0b013e3181f95b83

31 Kahn SR, Julian JA, Kearon C, Gu CS, Cohen DJ, Magnuson EA, Comerota AJ, Goldhaber SZ, Jaff MR, Razavi MK, Kindzelski AL, Schneider JR, Kim P, Chaer R, Sista AK, McLafferty RB, Kaufman JA, Wible BC, Blinder M, Vedantham $S$ and ATTRACT Trial Investigators: Quality of life after pharmacomechanical catheter-directed thrombolysis for proximal deep venous thrombosis. J Vasc Surg Venous Lymphat Disord 8(1): 8-23.e18, 2020. PMID: 31843251. DOI: 10.1016/j.jvsv. 2019.03.023

32 Brown CL, Rizer M, Alexander R, Sharpe EE 3rd and Rochon PJ: Pelvic congestion syndrome: systematic review of treatment success. Semin Intervent Radiol 35(1): 35-40, 2018. PMID: 29628614. DOI: $10.1055 / \mathrm{s}-0038-1636519$

33 Rabe E and Pannier F: [What is evidence-based in the treatment of chronic venous insufficiency?]. Internist (Berl) 61(12): 12301237, 2020. PMID: 33141265. DOI: 10.1007/s00108-02000899-6

34 Vanhoutte PM, Corcaud S and de Montrion C: Venous disease: from pathophysiology to quality of life. Angiology 48(7): 559567, 1997. PMID: 9242153. DOI: 10.1177/000331979704800702

35 Berger S, Andersen R, Dorenberg E, Meyer T, Weiss I, Smaastuen MC and Rosseland LA: Quality of life in patients with vascular malformations outside the central nervous system: Comparison with the general Norwegian population. J Plast Reconstr Aesthet Surg 72(12): 1880-1886, 2019. PMID: 31636028. DOI: 10.1016/j.bjps.2019.09.024

36 Calandriello L, Grimaldi G, Petrone G, Rigante M, Petroni S, Riso $M$ and Savino G: Cavernous venous malformation 
(cavernous hemangioma) of the orbit: Current concepts and a review of the literature. Surv Ophthalmol 62(4): 393-403, 2017. PMID: 28131871. DOI: 10.1016/j.survophthal.2017.01.004

37 Hassanein AH, Mulliken JB, Fishman SJ, Quatrano NA, Zurakowski D and Greene AK: Lymphatic malformation: risk of progression during childhood and adolescence. J Craniofac Surg 23(1): 149-152, 2012. PMID: 22337394. DOI: 10.1097/SCS. 0b013e3182413ea8

38 Liu AS, Mulliken JB, Zurakowski D, Fishman SJ and Greene AK: Extracranial arteriovenous malformations: natural progression and recurrence after treatment. Plast Reconstr Surg 125(4): 1185-1194, 2010. PMID: 20335868. DOI: 10.1097/PRS. 0b013e3181d18070

39 Rautio R, Saarinen J, Laranne J, Salenius JP and Keski-Nisula L: Endovascular treatment of venous malformations in extremities: results of sclerotherapy and the quality of life after treatment. Acta Radiol 45(4): 397-403, 2004. PMID: 15323391. DOI: $10.1080 / 02841850410004913$

40 Berenguer B, Burrows PE, Zurakowski D and Mulliken JB: Sclerotherapy of craniofacial venous malformations: complications and results. Plast Reconstr Surg 104(1): 1-11; discussion 12-5, 1999. PMID: 10597669.
41 van der Linden E, Otoide-Vree $\mathrm{M}$ and Pattynama PM: Percutaneous treatment of peripheral vascular malformations in children: long-term clinical outcome. Cardiovasc Intervent Radiol 35(2): 316-324, 2012. PMID: 21562935. DOI: 10.1007/ s00270-011-0170-6

42 van der Linden E, Pattynama PM, Heeres BC, de Jong SC, Hop WC and Kroft LJ: Long-term patient satisfaction after percutaneous treatment of peripheral vascular malformations. Radiology 251(3): 926-932, 2009. PMID: 19336668. DOI: 10.1148/radiol.2513081579
Received July 4, 2021

Revised August 23, 2021 Accepted August 31, 2021 